\title{
AKULTURASI BUDAYA TIMUR TENGAH DI INDONESIA (Kedatangan Islam dan Pengaruh Budaya)
}

\author{
Ahans Mahabie \\ Institut Islam Mamba’ul 'Ulum Surakarta \\ Ahansmahabie@gmail.com
}

\begin{abstract}
From the history of Islamic conquest to various parts of the world, Indonesia was one of the countries that was visited on the journey and the struggle to spread the monotheistic religion. With the entry of Islam into Indonesia, there was an encounter with all forms of Middle Eastern / Arabic culture, especially Islam with the archipelago, and naturally the encounter experienced acculturation with the culture in Indonesia.

Indonesia as a country also has its own indigenous culture. Portraits of indigenous Indonesian culture can now be found in inland-inland areas such as the Tengger people found on Sukapura on the slopes of Mount Bromo near Tasar Malang, Samin communities in Blora, Central Java, Baduwi communities in southern Banten, Kubu communities in southern Sumatra and Jambi, Baliage communities in Tenganan Pegringsing Karang Asem in Bali, and the Toraja community in Central Sulawesi, the Dayak tribe consisting of Oloot, Olonaju, and Manyansiyung in the interior of Borneo, and the Asmat tribe in Irian Jaya. All of them still hold the original culture with several forms such as animism, dynamism, veteism, and shammanism.

The arrival of Islam to Indonesia in the First Century H / VII-VIII M resulted in this nation experiencing cultural acculturation between Middle Eastern culture and Indonesian culture. The evidence of acculturation can be felt in several aspects, including language, literature, arts and education
\end{abstract}

Keyword: the entry of Islam into Indonesia, cultural encounters, cultural mixing 


\section{Pendahuluan}

Pernahkah kita, pribumi Nusantara ini menyadari bahwa sebagian besar kebudayaan yang kita miliki ini adalah hasil dari pengaruh masuknya Islam ke Nusantara? Tanpa kita sadari apa yang kita pakai, apa yang kita lihat, dengar, dan katakan, serta yang kita lakukan sehari-hari bahkan yang ada didepan kita saat ini adalah hasil cipta, rasa, dan karsa dari wibawa dan kebesaran Timur Tengah/Arab, khususnya Islam yang pernah berjaya pada waktu itu. Sejarah dunia mengatakan, sejak Abad ke-6 era dinasti Umayah, Abad ke-8 era dinasti Abasiyah, dan Abad ke-10 di era dinasti Fatimiyah hingga era Ottoman yang mendirikan dinastinya di Konstatinopel pada $1453 \mathrm{M}$ ditengah puingpuing keruntuhan Bizantium, Islam dengan keagungan dan the great conquest-nya berada di puncak kejayaan ${ }^{1}$. Dari sejarah penaklukan Islam ke berbagai penjuru dunia, Indonesia adalah salah satu negara yang disinggahi dalam perjalanan dan perjuangan untuk menyebarkan agama monoteis itu. Dengan masuknya Islam ke Indonesia, maka terjadilah perjumpaan atas segala bentuk kebudayaan Timur Tengah/Arab khususnya Islam dengan Nusantara, dan dengan sendirinya perjumpaan itu mengalami akulturasi dengan budaya yang ada di Indonesia.

Tentang sejarah kejayaan Islam tidak di bahas dalam tulisan ini, akan tetapi keagungan, kewibawaan dan keperkasaan yang pernah dimiliki, hendaknya dijadikan renungan; bukan karena kepentingan, tapi sebuah kenyataan yang sudah semestinya menghiasi khazanah keilmuan yang akan melahirkan pemikiran, perkataan, perbuatan dan kebudayaan dalam masyarakat Indonesia. Perkembangan Islam di Indonesia telah berhasil memunculkan suatu kebudayaan atau cipta, rasa, dan karsa para pemeluknya dan Indonesia pada umumnya ${ }^{2}$. Sedang kebudayaan Islam itu sendiri adalah kebudayaan yang benar-benar disepakati dan tidak diragukan oleh para ahli sebagai kebudayaan yang datang dari Islam baik yang dihasilkan oleh umatnya, pemerintahannya, maupun sebagai manifestasi dari nilai-nilai ajaran Islam³ ${ }^{3}$ Maka dengan datangnya Islam ke Indonesia, besertanya pula kebudayaan Islam itu sendiri. Dalam tulisan ini penulis akan mencoba menguraikan apa dan bagaimana proses kebudayaan Islam itu mempengaruhi kebudayaan Indonesia.

\footnotetext{
${ }^{1}$ Colquhoun, R. Archibald, 1906 The North American Review, Vol. 182, No. 595, Pan-Islam, University of Northern Iowa. Accessed: 17/05/2010 04:49

2 Abdul Karim, 2007 Islam Nusantara, Pustaka Book Publisher, hal: 124

${ }^{3}$ Ibid, hal: 127
} 


\section{Pembahasan}

a. Budaya asli Indonesia

Jauh sebelum Islam masuk dan membawa pengaruhnya di indonesia, yang sebelumnya telah terlebih dahulu disinggahi, didiami dan dipengaruhi oleh beberapa Negara dan kebudayaannya yakni India dan Cina, Negara yang berada diatas garis khatulistiwa ini mempunyai budaya yang tentunya menjadi identitas dan karakter Nusantara yang sudah mendarah daging sejak dahulu dan tersebar darisabang sampai merauke.

Prof. M. Abdul Karim menjelaskan bahwa potret budaya asli Indonesia sekarang ini bisa dijumpai di wilayah pedalaman-pedalaman seperti masyarakat Tengger yang terdapat di Sukapura lereng gunung Bromo dekat Tasar Malang. Masyarakat Samin di Blora Jawa Tengah, masyarakat Baduwi di Banten selatan, masyarakat Kubu di Sumatera selatan dan Jambi, masyarakat Baliage di Tenganan Pegringsing Karang Asem di Bali, dan masyarakat Toraja di Sulawesi Tengah, suku Dayak yang terdiri dari Oloot, Olonaju, dan Manyansiyung di pedalaman Kalimantan, dan suku Asmat yang terdapat di Irian Jaya. Mereka seluruhnya masih memegang budaya asli dengan beberapa isme seperti animisme, dynamisme, veteisme, dan shammanisme ${ }^{4}$.

Animisme, ialah keyakinan bahwa setiap benda di alam ini memiliki roh, animus atau jiwa yang diyakini memiliki pengaruh bagi manusia, seperti jimat- jimat, tongkat, keris, cincin dan benda-benda lain yang diyakini mempunyai roh atau penghuni. Bahkan di Jawa, pasca Islam pun masih ada yang percaya akan faham ini ${ }^{5}$. Dynamisme, ialah kepercayaan di mana setiap benda memiliki kekuatan seperti gunung-gunung, batu-batu, dan sebagainya. Di Dayak misalnya, dikenal adat memotong kepala (mengajau), dan di Toraja, wanita-wanita menanam padi dengan rambut terurai karena kekuatan yang terletak di dalam rambut. Di keraton Yogyakarta dan Solo, orang-orang tjebol, buta (buto), bule dianggap sakti, didekatkan kepada raja untuk menambah kesaktian. Veteisme, yakni suatu faham yang berkeyakinan bahwa setiap benda memiliki mana (kekuatan ghaib).

\footnotetext{
${ }^{4}$ Abdul Karim, 2007 Islam Nusantara, Pustaka Book Publisher, hal: 136

${ }^{5}$ Keterangan lengkap bisa dibaca di buku Religion in Java (Clifford Geertz)
} 
Shammanisme, ialah paham keyakinan bahwa ruh dapat menjelma pada seseorang, di Sumatera dikenal pawang, di Jawa dalang, dan jatilan.

b. Evolusi Budaya

Berangkat dari asumsi bahwa Indonesia mempunyai budaya asli, sebelum mengalami akulturasi dan perkembangan dengan budaya-budaya lain yang datang dan mempengaruhi budaya yang ada, maka tahapan perkembangan budaya di Indonesia dapat dibagi menjadi 5 periode, 1) Pra-Perkembangan Budaya, 2) Perkembangan budaya Hindu, 3) Perkembangan Budaya Budha, 3) Perkembangan Budaya Islam, 4) Pasca Perkembangan Budaya Islam6.

Dalam periode pra-perkembangan, menurut catatan Prof Abdul Karim Indonesia relatif tidak ada pengaruh dari budaya luar. masyarakat animisme, dynamisme, veteisme, dan shammanisme yang berada di pedalaman adalah potret periode ini. Sesudah pra-perkembangan budaya datanglah perembesan budaya Hindu dan berkembang pada $78 \mathrm{M}^{7}$ dan mencapai puncak pada jaman Majapahit, yang eksistensinya dengan mudah dikenali dari peninggalan-peninggalan batu bertulis, monumen-monumen seperti candi Prambanan di Yogyakarta, candi Trowulan, Brahu, Bajangratu, Ringin Lawang, Gentong, dan candi Tikus di Mojokerto, relief-relief yang hingga kini masih terpelihara di Bali (pura) kalender Saka yang masih digunakan oleh mayarakat Samin, Tengger, Badui, dan di pulau Bali. Bahasa Sansekerta sebagai bahasa agama Hindu dengan huruf ha, na, ca, ra, ka juga berpengaruh kuat hingga kini dan dianggap sakral seperti, Ratu, Pramesyari, Pancasila, Bhineka Tunggal Ika, Panca Satya dan sebagainya. Pada periode perkembangan agama yang didirikan oleh Siddharta Gautama yakni Budha, lebih menekankan kepada moral dan etika yang sangat berguna untuk penguasaan diri, menuntun manusia untuk berbuat baik kepada sesama agar bisa mencapai Nirwana yaitu kehidupan Abadi tanpa penderitaan, meningkatkan budi daya agar kehidupan manusia lebih terangkat dan mencapai kebahagiaan. Candi Borobudur di Magelang adalah peninggalan yang melambangkan falsafah agama Budha dan menjadi salah satu keajaiban dunia.

\footnotetext{
${ }^{6}$ Abdul Karim, 2007 Islam Nusantara, Pustaka Book Publisher, hal: 138-147

${ }^{7}$ Ibid, hal: 140
} 
Pada Abad ke-17 ada saatnya tatanan lama yang terpengaruh indianisasi itu terguncangkan ${ }^{8}$. Kedatangan Islam di Indonesia mendorong revolusi besar ke dalam tatanan kehidupan masyarakat. Hampir seluruh aspek tata kehidupan diubah menjadi aturan-aturan yang berdasarkan kaidah-kaidah seperti, tauhid yang patut didipuja dan diyakini memiliki kekuasaan Yang Maha Besar ialah Allah Yang Tunggal, manusia dihadapan Allah memiliki derajat yang sama, kemuliaan diperoleh apabila manusia bertaqwa kepada Allah, kehidupan manusia dalam masyarakat terikat dalam kesatuan dan persatuan yang terbagi menurut susunan kemasyarakatan, kehidupan bermasyarakat diatur oleh aturan-aturan yang dibuat secara bermusyawarah sesuai dengan kehendak bersama, dan Nikmat Allah yang tertuang di langit, bumi dan diantara keduanya, harus dinikmati secara merata ${ }^{9}$.

Masalah akidah agama Islam tidak dibahas dalam tulisan ini, akan tetapi sejak kedatangan dan perkembangannya di bumi Nusantara, yang pada tahun 1988 tercatat hampir 175 juta orang jumlahnya dan menduduki peringkat lima di dunia sesudah Cina, India, Uni Soviet dan Amerika Serikat, menurut statistik resmi, 90\% dari jumlah penduduk itu beragama Islam. Dengan demikian Indonesia merupakan negeri yang paling banyak penduduknya di dunia Islam, jauh melebihi Pakistan (81 juta), dan Bangladesh (77 juta) ${ }^{10}$. Maka sudah barang tentu kebudayaan yang dibawa oleh Islam mempengaruhi kebudayaan yang ada di Indonesia.

c. Masuknya Islam di Indonesia

Dari beberapa wacana yang ada, sejarah masuknya islam di Indonesia menjadi perdebatan oleh karena tidak ada data yang kuat tentang kepastian kapan, dimana, siapa, dan bagaimana Islam masuk ke Indonesia. Akan tetapi masuknya Islam di bumi Nusantara ini merupakan salah satu proses yang sangat penting dalam sejarah kebudayaan Indonesia. Para sejarawan sepakat bahwa tempat asal kedatangan Islam ke Indonesia terbagi menjadi dua, dari Timur Tengah/Arab dan

\footnotetext{
Utama ForumJakarta-Paris École Française d'extrême-Orient Jakarta, hal: 50

${ }^{9}$ Abdul Karim, 2007 Islam Nusantara, Pustaka Book Publisher, hal:144

${ }^{10}$ Denys Lombard, 2008, hal: 84
}

${ }^{8}$ Denys Lombard, 2008 Nusa Jawa Silang Budaya 2, Terj, Le Carrefour Javanais, GramediaPustaka 
Anak Benua India, dan dapat dipastikan tidak ada sejarawan yang berpendapat secara eksplisit bahwa Islamisasi Nusantara berasal dari China ${ }^{11}$.

Dari Hasil Seminar Masuknya Islam ke Indonesia di Medan tercatat bahwa Islam telah datang untuk pertama kali ke Indonesia pada Abad I H/ VII-VIII M, yakni sejak permulaan perkembangan Islam ${ }^{12}$. Menurut Profesor M.C. Ricklefs, para pedagang muslim sudah ada di sebagian wilayah Indonesia selama beberapa Abad sebelum Islam menjadi agama yang mapan dalam masyarakat-masyarakat lokal ${ }^{13}$. Kalau Yusuf dkk mengatakan bahwa beberapa ahli sejarah dari Timur Tengah seperti Crawfurd, Keijzer, Naimann, de Hollander. Dari Indonesia-Melayu seperti Hasjmi, al-Attas, Hamka, dan Azra. Dari India seperti Pijnnapel, Hurgronje, Mouquette, Morison, Kern, Winsted, Fatimi, Vlekke, Mukti Ali, dan Schrieke mencatat bahwa Islam masuk ke Nusantara pada Abad ke-13 M, maka beberapa Abad sebelum itu tentunya Islam sudah terlebih dahulu masuk bersama para pedagang muslim, akan tetapi belum berkembang.

Dari beberapa statemen di atas bisa disimpulkan meskipun belum sepenuhnya bisa dijadikan acuan. Sebagaimana dikatakan oleh Azyumardi Azra bahwa Islam memang sudah datang dan diperkenalkan pada Nusantara pada awal Abad Hijriah, akan tetapi pengaruh Islami baru tampak nyata, dan proses Islamisasibaru mengalami ekselerasi antara Abad ke-12 dan 16 M. Islam menunjukkan eksistensinya di Sumatra pada Abad ke-13 dan di Jawa pada Abad ke-15 setelah berhasil memasuki wilayah kekuasaan politik yang selanjutnya dipakai untuk mendapatkan dukungan rakyat agar mereka memeluk Islam.

Berdasarkan bagaimana masuknya Islam di Indonesia, Prof. M. Abdul Karim ${ }^{14}$ mengelompokkannya menjadi dua jalur, yakni laut dan darat. Dari jalur laut, dengan rute dari Aden menyisir pantai menuju Maskat, Raisut, Siraf, Guadar, Daibul (Debal), pantai Malabar yang meliputi Gujarat, Keras (ibu kota kerajaan Kadangalar), Quilon, dan Kalicut. Kemudian menyisir pantai Karamandel seperti

\footnotetext{
${ }^{11}$ Abdul Karim, 2007 Islam Nusantara, Pustaka Book Publisher, hal:325

${ }^{12}$ Ibid, hal:326

${ }^{13}$ Ricklefs, M. C,2005 Sejarah Indonesia Modern 1200-2004, Terj, A History of Modern
} Indonesia Since c. 1200 Third Edition, PT Serambi Ilmu Semesta Jakarta, hal: 27

${ }^{14}$ Ibid, hal:323-324 
Saptagram ke Chitagong (pelabuhan terbesar di bangladesh), Akyab (sekarang wilayah Myanmar) selat Malaka, Peureulak (Aceh timur), Lamno (pantai barat Aceh), Barus, Padang, Banten, Cirebon, Demak, Jepara, Tuban, Gresik, Ampel, Makasar, Ternate, dan Tidore. Rute yang lain dari Aden menuju pantai Malabar (dengan Quilon sebagai pelabuhan besar) di Deccan, selat Cylon (memisahkan India dan Srilangka) kemudian dilanjutkan ke Malaka (alam melayu) melewati Singapura (sekarang) ke Patani sampai ke Kanton. Sementara itu jalur darat adalah menempuh rute dari Mekah ke Madain, Kabul, Kashmir, Singkiang (sekarang Sinzhiang), Zaitun, Kanton ke alam Melayu yang dikenal sebagai jalur Sutera. Untuk itu, pada Abad Abad pertama Hijriah di Kanton sudah ada koloni Arab muslim. Sambil berdagang, mereka berdakwah menyebarkan agama Islam kepada penduduk setempat. Akhirnya Islam yang diterima secara evolutif dengan damai (penetration pacifique) dapat mengubah tatanan masyarakat.

Tanpa menafikan anggapan bahwa Islam masuk ke Indonesia dengan damai namun pada nantinya menuai perdebatan dengan adanya penaklukan melalui perang yang berlangsung antara Demak melawan Mojopahit, dan Banten melawan Pakuan, serta sosok sunan Kudus sebagai pemimpin perang ${ }^{15}$, dominasi Islam tampak pada tingkat sosial dan politik dalam kemajuan pesat berbagai kesultanan, dari Aceh sampai Ternate dan kepulauan sulu, dan itulah gejala terpenting pada Abad ke-16, ke17 dan ke-18. Sebagaimana pada permulaan tarikh Hijriah, bersama agama Islam kebudayaan-kebudayaan yang terpencar-pencar dari kota- kota kuno Timur Tengah, kota-kota Suriah, Iran, Koptik, Yunani, dapat disatukan dan diperkuat, maka di sini pun agama itu menjadi ikatan, ciri khas bersama, bagi semua yang demi perniagaan dan pelayaran, mendatangi pelabuhan-pelabuhan baruyang sedang terbentuk ${ }^{16}$.

d. Akulturasi kebudayaan Timur Tengah (Islam) dengan kebudayaan Indonesia Menurut

Doeliman, budaya yang ada di Indonesia merupakan akulturasi dari berbagai macam budaya yang sangat kompleks, karena Indonesia merupakan jalur

\footnotetext{
15 Denys Lombard, 2008, hal: 126

${ }^{16} \mathrm{Ibid}$, hal:50
} 
lalu lintas perdagangan dan tempat persinggahan para penjelajah ${ }^{17}$. Dengan masuknya Islam ke Nusantara, maka dengan sendirinya masuklah pula berbagai budaya bersamanya yang akan menambah kompleksnya budaya melalui akulturasi dengan beragam kebudayaan yang sudah ada. Artinya pengaruh budaya Indonesia tidak hilang oleh budaya yang datang tapi terjadi akulturasi percampuran diantara dua kebudayaan tersebut yang saling mempengaruhi satu dengan yang lainnya. Hal ini dikarenakan budaya di Indonesia yang begitu kental, begitu mengakar dan mendarah daging pada suku-suku dan ras asli yang tersebar diseluruh penjuru bumi Nusantara.

e. Proses percampuran budaya

Dalam akulturasi sebuah kebudayaan, tentunya tidak semua budaya yang sudah ada terpengaruh dengan budaya baru atau sebaliknya, budaya baru belum tentu mendominasi budaya lama. Begitu juga dengan proses percampuran budaya antara Timur Tengah yang dibawa Islam dan Indonesia yang sudah mempunyai budaya. Proses percampuran berbagai macam kebudayaan tersebut, oleh Prof Abdul Karim dibagi menjadi tiga $\left.{ }^{18}, 1\right)$ Dominasi budaya Islam, bukti dari domninasi Islam dapat dilihat dalam hal ritual-ritual Islam, seperti peralatan- peralatan yang digunakan saat shalat (sajadah,tasbih,dan sebagainya), kelembagaan zakat, wakaf, dan pengurusan pelaksanaan haji. 2) Percampuran antara keduanya, percampuran antara dua budaya dapat dilihat pada bangunan-bangunan masjid bentuk joglo, pakaian, lagu, kasidah, tahlil, dan sebagainya. 3) Membentuk corak tersendiri, dalam proses ini terjadi akulturasi yang sama kuatnya sehingga membentuk budaya baru yang masing-masing budaya ikut mewarnai budaya yang baru itu secara berimbang seperti system pemerintahan (pancasila), system permusyawaratan, dan lain sebagainya.

f. Bukti-bukti akulturasi

Dari tiga macam proses akulturasi budaya dengan budaya yang ada di Indonesia diatas, maka dalam tulisan ini akan mencoba menguraikan secara umum budaya Indonesia yang terpengaruh budaya Timur Tengah/Islam.

\footnotetext{
${ }^{17}$ Abdul Karim, 2007 hal: 152

${ }^{18}$ Abdul Karim, 2007, hal: 153
} 
1. Bahasa

Seperti halnya bahasa Sansekerta yang dibawa oleh agama Budha dan sampai hari ini masih ada pengaruhnya seperti, Ratu, Pramesyari, Pancasila, Bhineka Tunggal Ika, Panca Satya dan sebagainya, maka Islam tentu dengan bahasa nasional mereka yakni Arab. Menurut penelitiannya di sekitar Yogyakarya dan Surakarta, Prof. Abdul Karim menyatakan bahwa akulturasi bahasa terjadi secara adopsi dengan penyesuaian pengucapan, seperti pada huruf-huruf tertentu yang bagi orang Jawa sangat sulit melafalkannya'19 seperti huruf 'ain ('alamin) dibaca ngain (ngalamin), kha dan ha dibaca ka, huruf dzo' dan dho' dibaca "L" (wudhu dibaca wulu dan dzuhur menjadi luhur), lafz al-jalalah (Allah) diucapkan Alloh (diantara "o" dengan "a”), dan sebagainya.

Adopsi dengan penyesuaian pengucapan juga digunakan orang Indonesia dalam penyebutan nama seperti nama orang Abdul Rahim dibaca durakim, Abdul Hamid dibaca dolkamid, Sami'un dibaca Samingun. Dalam pemberian nama terjadi akulturasi terbuka ${ }^{20}$, ada yang menggunakan nama Islam seperti Muhammad, Ali, Abu Bakar dan sebagainya. Dan ada juga yang menggabungkan antara budaya Indonesia dengan Arab seperti Edy Toyib, Muhammad Djoko, Ahmad Soekarno dan sebagainya. Selain nama orang dapat dijumpai bahasa dipakai untuk menyebut nama tempat seperti Darul Ulum (Universitas di Jombang), Bahrul Ulum (Ponpes di Jombang), Nurul Jadid (Ponpes di Probolinggo) dan sebagainya.

2. Sastra

Masuknya Islam ke indonesia juga mempengaruhi dunia sastra di nusantara. Sebelum datangnya Islam, dunia sastra seperti cerita atau dongeng di Indonesia berisikan tentang ajaran-ajaran Hindu-Budha seperti Hikayat Mahabharata yang sudah menjadi buku suci orang Hindu karena didalamnya menerangkan cara hidup orang Hindu, susunan masyarakat dan politiknya serta pemikiran dan kebudayaan orang Hindu ${ }^{21}$, Pandawa Lima, dan lain sebagainya. Dan setelah datangnya Islam, lambat laun berubah menjadi sastra Islam sebagai

\footnotetext{
${ }^{19}$ Abdul Karim, 2007, hal: 156

${ }^{20}$ Ibid, hal:160

21 Yock Fang, Liaw, 1975 Sejarah Kesusastraan Melayu Klassik, Pustaka Nasional Singapura,
} hal: 49 
sastra yang datang bersama-sama dengan kedatangan Islam. Sastra semacam ini mempunyai tujuan-tujuannya: Menceritakan keagungan agama Islam, serta nabinabi dan pahlawan-pahlawannya supaya para pendengar suka masuk Islam, dan memperdalam keimanan mereka.

Menurut isinya, sastra Islam dibahagi 5 golongan, cerita Nabi Muhammad, para sahabat, cerita nabi seperti Kitab Anbiya, Hikayat Yusuf dan lain-lain, penyebar dan pahlawan Islam seperti Iskandar Zulkarnain, Amir Hamzah dan Saif Dzul-Yazan, dan cerita Khayalan yang timbul di Nusantara ${ }^{22}$. Dari semua cerita-cerita yang ada bermaksud menerangkan semua nilai-nilai agama Islam, dan mengajak para pembaca dan pendengar untuk masuk Islam. Salah satu cerita menarik dan sangat berpengaruh dalam masyarakat hinga saat ini adalah hikayat Raja Jumjumah yang bercerita tentang siksa kubur dan neraka (Jumsari, 1979: 9), dan menguatkan bahwa sastra ini telah dipengaruhi oleh Timur Tengah/Islam, cerita itu bahasa Melayu tapi menggunakan tulisan Arab ${ }^{23}$. Pengaruh budaya Islam dalam bidang sastra yang lain juga terlihat pada tembang Ilir-ilir, yang baru-baru ini di populerkan oleh Emha Ainun Najib, didalam tembang yang dibuat Kanjeng Sunan Ampel dalam usahanya untuk mengajak para masyarakat untuk bangkit dari tidur panjanganya itu terdapat kisi-kisi Islam ${ }^{24}$.

3. Kesenian

Akulturasi budaya di bidang seni baik seni ukir, maupun seni pahat, dan kreatifitas dalam bentuk kerajinan, arsitek, monument, kaligrafi, dan mozaik yang terlihat pada interior bangunan rumah atau masjid-masjid ${ }^{25}$. Dalam bidang arsitektur, akulturasi budaya menghasilkan bentuk bangunan menara yang dibuat seperti pencakar langit dengan arsitektur yang indah. Selain digunakan sebagai tempat orang memanggil kaum muslim untuk shalat/adzan, bangunan itu berfungsi juga untuk mengawasi hilal. Seni kaligrafi disamping telah digunakan untuk menghiasi dinding-dinding masjid dengan berbagai macam

\footnotetext{
${ }^{22}$ Yock Fang, Liaw, 1975, hal: 132

${ }^{23}$ Data tersebut diperoleh penulis dari penelitian Filologi di Perpustakaan Nasional, Jl. Salemba Jakarta Pusat hari senin sampai rabu tanggal 18 sampai 20 Januari 2010

${ }^{24}$ Diadopsi dari renungan Ilir-ilir oleh Emha Ainun Najib

${ }^{25}$ Abdul Karim, 2007, hal: 155
} 
gaya seperti Naskhi, Riq'ie, Tsulutsi, Kufi, Diwani, Farisi, dan sebagainya ${ }^{26,}$ kesenian itu juga diajarkan di bangku sekolah di beberapa lembaga pendidikan seperti Pondok pesantren dan Universitas-universitas Islam, dan masih banyak lagi akulturasi kesenian yang lain yang mungkin tidak tersebut dalam uraian tulisan ini.

\section{Pendidikan}

Dari semboyan bahwa Islam adalah "din wad-daulah" atau "ibadah dan kebudayaan27" dan sabda Nabi "Sampaikan olehmu apa yang datang dari saya, meskipun satu ayat", bisa disimpulkan bahwa pembawa Islam ke Indonesia yang notabenenya pedagang muslim, selain berdagang mereka juga merasa berkewajiban untuk menyebarkan agama Islam sebagai wujud ibadah. Dari menggunakan waktu senggang mereka setelah berdagang guna berdakwah dan menyampaikan ajaran-ajaran Islam, usaha merekan berhasil dan terus berkembang ke segenap penjuru tanah air. Banyak perguruan-perguruan yang dipimpin oleh seorang ulama dan diikuti oleh beberapa orang murid. Di Samudra Pasai tokoh yang terkenal dalam menyebarkan agama Islam antara lain Hamzah Fansuri, Abdur Rauf Singkel, dan Nuruddin Ar-Raniri yang berasal dari Gujarat, suatu tempat yang banyak dipengaruhi oleh aliran tasawuf. Dan di Jawa, terutama di pesisir utara, para pemimpin madrasah dan gerakan dakwah Islam dikenal dengan sebutan wali yang kemudian terkenal dengan julukan wali sanga dengan panggilan sunan $^{28}$.

Dari perjuangan para sunan menyebarkan Islam, kian hari pengikutnya bertambah banyak maka didirikan tempat-tempat yang disebut pesantren yang dilengkapi pondokan-pondokan yang terletak dipinggiran kota. Materi-materi yang diajarkan didalamnya dimulai dari al-Quran, dilanjutkan dengan bahasa Arab dan ilmu fiqih dari empat madzhab yang terkenal, baru kemudian akaid, akhlak, dan tasawuf. Berbeda dengan dikota-kota, masyarakat mendirikan madrasah-madrasah yang dibina dan dikembangkan secara modern olehlembaga-lembaga Islam seperti Muhammadiyah, Persis, NU, dan sebagainya.

\footnotetext{
${ }^{26}$ Ibid, hal: 157

${ }^{27}$ Steenbrink, Karel A, 1984 Beberapa Aspek Tentang Islam Di Indonesia Abad Ke-19, P. T Bulan Bintang Jakarta, hal: 9

${ }^{28}$ Abdul Karim, 2007, hal: 149
} 
Dalam perkembangan yang terbatas, pesantren dan madrasah dapat dikelola dan diurus oleh perorangan yang biasa disebut dengan kiai (berasal dari bahasa Persi kia yang berarti orang yang menonjol dalam suatu bidang) setelah berkembang sedemikian rupa madrasah tidak lagi bisa diurus oleh per orang sehingga dibentuklah organisasi yang bergerak dalam pendidikan Islam ${ }^{29}$.

Dari beberapa bentuk akulturasi budaya yang disajikan diatas mungkin belum sepenuhnya mewakili bentuk-bentuk akulturasi yang ada. Akan tetapi sesuai dengan tujuan tulisan yang hanya ingin menguraikan apa dan bagaimana proses kebudayaan Islam itu mempengaruhi kebudayaan Indonesia, mungkin sudah cukup merepresentasikan.

\section{Kesimpulan}

Dari semua hasil penelusuran dan penjelasan yang diuraikan dalam tulisan ini tentang pengaruh budaya Timur Tengah/Arab dengan budaya Indonesia, bisa ditarik kesimpulan bahwa berkembangnya Islam di Nusantara adalah awal dari segala perubahan budaya yang sebelumnya sudah mengakar di masyarakat Indonesia yakni Hindu-Budha kepada budaya baru dengan kepercayaan baru yakni Islam. Dan dengan pengaruh kebudayaan yang di berikan melalui akulturasi budaya-budaya yang ada seperti bahasa, sastra, seni, pendidikan, dan sebagainya, kebesaran Islam dengan budayanya telah mengantarkan Indonesia menjadi Negara yang paling banyak penduduknya di dunia Islam.

\section{Daftar Pustaka}

Colquhoun, R. Archibald, 1906 The North American Review, Vol. 182, No. 595, Pan-Islam, University of Northern Iowa. Accessed: 17/05/2010 04:49

Karim, M. Abdul, 2007 Islam Nusantara, Pustaka Book Publisher Yogyakarta

2009 Sejarah Pemikiran dan Peradaban Islam, Pustaka Book Publisher Yogyakarta Lombard, Denys, 2008 Nusa Jawa Silang Budaya 2, Terj, Le Carrefour Javanais, Gramedia Pustaka Utama Forum Jakarta-Paris École Française d'extrême-Orient Jakarta Partanto, A Pius dan Al Barry, M. Dahlan

\footnotetext{
${ }^{29}$ Abdul Karim, 2007, hal: 150
} 
13 Mamba'ul 'Ulum, Vol.16 No.1, April 2020:1-13

1994 Kamus Ilmiah Populer, Arkola Surabaya

Ricklefs, M. C,

2005 Sejarah Indonesia Modern 1200-2004, Terj, A History of Modern Indonesia

Since c. 1200 Third Edition, PT Serambi Ilmu Semesta Jakarta

Steenbrink, Karel A,

1984 Beberapa Aspek Tentang Islam Di Indonesia Abad Ke-19, P. T Bulan Bintang Jakarta

Yock Fang, Liaw,

1975 Sejarah Kesusastraan Melayu Klassik, Pustaka Nasional Singapura 